Journal of the

MARINE Biological AsSOCIATION

of the United Kingdom

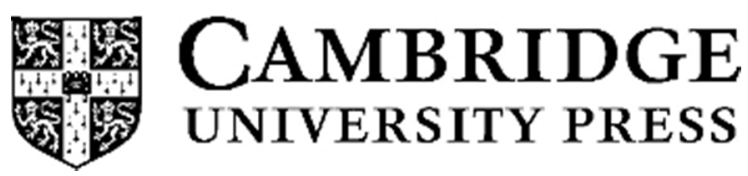

\title{
The role of cryptic dispersal in shaping connectivity patterns of marine populations in a changing world.
}

\begin{tabular}{|r|l|}
\hline Journal: & Journal of the Marine Biological Association of the United Kingdom \\
\hline Manuscript ID & JMBA-07-16-RE-0203.R1 \\
\hline Manuscript Type: & Review \\
\hline Date Submitted by the Author: & n/a \\
\hline Complete List of Authors: & \begin{tabular}{rl|} 
David, Andrew; Clarkson University, Biology \\
Loveday, Benjamin ; Plymouth Marine Laboratory
\end{tabular} \\
\hline Abstract: & $\begin{array}{l}\text { oceanography, modelling, genetics, larvae, introduction, invasive, species, } \\
\text { aquaculture }\end{array}$ \\
\hline & $\begin{array}{l}\text { Genetic connectivity directly shapes the demographic profile of marine } \\
\text { species, and has become one of the most intensely researched areas in } \\
\text { marine ecology. More importantly, it has changed the way we design and } \\
\text { describe Marine Protected Areas across the world. Population genetics is } \\
\text { the preferred tool when measuring connectivity patterns, however, these } \\
\text { methods often assume that dispersal patterns are 1) natural and } 2) \text { follow } \\
\text { traditional metapopulation models. In this short review, we formally } \\
\text { introduce the phenomenon of cryptic dispersal, where multiple introductory } \\
\text { connectivity estimates. We also discuss the evolutionary consequences of } \\
\text { cryptic dispersal and advocate for a cross-disciplinary approach that } \\
\text { incorporates larval transport models into population genetic studies to } \\
\text { provide a level of oceanographic realism that will result in more accurate } \\
\text { estimates of dispersal. As globalized trade continues to expand, the rate of } \\
\text { anthropogenic movement of marine organisms is also expected to increase } \\
\text { and as such, integrated methods will be required to meet the inevitable } \\
\text { conservation challenges that will arise from it. }\end{array}$ \\
\hline
\end{tabular}


1 Title: The role of cryptic dispersal in shaping connectivity patterns of marine populations in a

2 changing world.

3

4 Running Title: Cryptic dispersal in marine populations

5

6 Short Review Article

7

8 Authors: Andrew A. David ${ }^{\mathrm{a}^{*}}$, Benjamin R. Loveday ${ }^{\mathrm{b}}$

$9{ }^{\mathrm{a}}$ Department of Biology, Clarkson University, Potsdam, NY - 13699, USA

10 blymouth Marine Laboratory, Prospect Place, Plymouth, PL1 3DH, United Kingdom

11

12

*Corresponding author: Department of Biology, 8 Clarkson Avenue, Clarkson University, Potsdam NY

13

13699, Box 5805. Tel: (+1)3152684355, email: $\underline{\text { adavid@ clarkson.edu }}$

14

15

16

17

18

19

20

21

22

23

24

25

26 
27 Abstract

28 Genetic connectivity directly shapes the demographic profile of marine species, and has become one of

29 the most intensely researched areas in marine ecology. More importantly, it has changed the way we

30 design and describe Marine Protected Areas across the world. Population genetics is the preferred tool

31 when measuring connectivity patterns, however, these methods often assume that dispersal patterns are

32 1) natural and 2) follow traditional metapopulation models. In this short review, we formally introduce

33 the phenomenon of cryptic dispersal, where multiple introductory events can undermine these

34 assumptions, resulting in grossly inaccurate connectivity estimates. We also discuss the evolutionary

35 consequences of cryptic dispersal and advocate for a cross-disciplinary approach that incorporates

36 larval transport models into population genetic studies to provide a level of oceanographic realism that

37 will result in more accurate estimates of dispersal. As globalized trade continues to expand, the rate of

38 anthropogenic movement of marine organisms is also expected to increase and as such, integrated

39 methods will be required to meet the inevitable conservation challenges that will arise from it.

Keywords: oceanography, modelling, genetics, larvae, introduction, invasive, species, aquaculture, vector, 44 ballast 


\section{Introduction}

Understanding the dispersal capacity of marine organisms is the most widely researched, albeit least understood area in marine ecology (Cowen \& Sponaugle, 2009; Hellberg, 2009; Buston \&D’Aloia, 2013; Crook et al. 2015). Dispersal patterns govern population connectivity, which in turn influences important ecological and evolutionary processes (Levin, 2006). As such, the study of dispersal dynamics is fundamental to marine biodiversity and conservation research where it can help distinguish distinct genetic lineages which are of evolutionary importance when designing marine protected areas (MPAs) (Palumbi, 2003; Von der Heyden, 2009). Understanding the dispersal capacity of an organism is also crucial for assessing the invasion potential of non-indigenous species (NIS) as it can serve as a reliable proxy for measuring connectivity and genetic diversity in recently introduce populations (Roman \& Darling, 2007). In many fish and invertebrates, larval movement is ultimately responsible for dispersal on both local and regional scales and for sessile animals such as tunicates, barnacles and sponges, to name a few, it is the sole means of natural dispersal. However, due to the large numbers and minute sizes of larvae, along with the vast expanse of the world's oceans, tracking and quantifying dispersal has been notoriously difficult and some would argue, impossible (Metaxas \& Saunders, 2009; Cowen \& Sponaugle, 2009; Selkoe \& Toonen. 2011). As a result, alternative approaches have been developed which offers indirect but pragmatic estimates of connectivity.

Population genetics has emerged as one of these alternatives and has proven to be a powerful tool for measuring dispersal in the marine realm (Levin, 2006). When estimating dispersal capacity, population genetics assumes that larval dispersal patterns follow traditional metapopulation models (e.g. island, stepping stone, etc) and that the movement of alleles can be traced back to the natural movement of individuals. The use of mitochondrial genetic markers (mtDNA) and nuclear genetic markers (nDNA) are often employed. MtDNA markers such as the cytochrome b (Cyt b) and cytochrome c oxidase I (COI) genes have high rates of sequence evolution and are often used to gain insights into past events that have helped shape current genetic patterns (Avise, 2009). These markers are often integrated into a 'molecular clock' which can provide divergence estimates that parallels important geological events such as sea level 
rise and glacial retreats. In contrast, nDNA markers such as SNPs (single nucleotide polymorphisms) show more variability when used in large quantities and are used to gain insights into the contemporary movement of organisms. Higher resolution nuclear markers such as AFLPs (Amplified Fragment Length Polymorphisms) and microsatellites are much more variable than both mitochondrial genes and SNPs and usually provide deeper insights into recent dispersal events. While there is no 'ideal' marker, utilizing both mtDNA in combination with nDNA markers provides a more holistic understanding of the genetic architecture and connectivity patterns of populations (Karl et al. 2012).

The results of population genetic studies are often interpreted within the context of the species' larval developmental strategy. For example, traditional life history theory posits that organisms producing larvae with long planktonic larval duration (PLD) phases will be able to disperse to far distances and therefore be expected to show high levels of connectivity among spatially separated populations. This was based on the assumption that larvae act as passive particles and are at the mercy of the diffusive forces of the pelagic environment (Selkoe \& Toonen, 2011). In contrast organisms that exhibit abbreviated larval development (short PLDs) or direct development (no planktonic phase) are expected to show high recruitment rates and hence low levels of population connectivity. A meta-analysis by Shanks (2009) provides the most comprehensive dataset thus far showing an acceptable correlation $\left(\mathrm{R}^{2}=0.48\right)$ between PLD and dispersal distance. While genetic studies have found this to be true for many cases, recent studies have shown increasing numbers of exceptions. These exceptions are important because they allude to a more complex picture of dispersal in the marine realm. For example, environmental heterogeneity such as haloclines, thermoclines, strong current systems, vertical stratification of the water column, bathymetry and upwelling cells are all oceanographic features that can act as dispersal barriers, limiting connectivity of a species regardless of PLD (Robinson et al. 2011). These barriers are sometimes known as phylogeographic breaks because they are usually associated with known biogeographic boundaries that can limit gene flow, thereby facilitating the formation of distinct genetic lineages (Figure 1). On the other end, unorthodox dispersal vectors such as rafting has been shown to significantly increase population connectivity of species that produces larvae with short PLDs phases or are direct developers (Nikula et al. 
2013; Cumming et al. 2014; Donald et al. 2015). Independent of the aforementioned factors, genetic estimates of dispersal are further complicated by issues such as inadequate and inaccurate taxon sampling (the latter refers to potential cryptic species) (Wysor et al. 2002; Wrange et al. 2016), chaotic genetic patchiness, where significant genetic structure is observed in the absence of dispersal barriers (Kesaniemi et al. 2014) and asymmetric dispersal patterns, where diversity across sites is wholly driven by diversity at upstream locations thereby masking true patterns of connectivity and demography (Pringle \& Wares, 2007; Wares \& Pringle, 2008).

A recent study by David et al. (2016) coined the term, cryptic dispersal - a phenomenon where the anthropogenic movement of organisms via vectors such as the aquaculture trade and transfer of ballast water may erode phylogeographic signal, thereby reducing the power of genetic markers and in doing so render gene flow and genetic connectivity estimates inaccurate. Cryptic dispersal therefore adds another dimension of complexity to dispersal dynamics in the marine realm. The primary aim of this review is to formally introduce the concept of cryptic dispersal, highlight some of the more recent studies that are either potential or definitive cases of cryptic dispersal and briefly discuss the evolutionary consequences of this phenomenon. This review does not aim to exhaustively review the effects of introductions on the genetic architecture of populations, as this general topic has received considerable coverage in the literature, but rather to hone in on the least understood and most inconspicuous effect of human-mediated introductions. In this review, we distinguish 'intentional' vectors such as aquaculture and shipping from rafting and attachment to floating structures, which are often inconsistent and have both a biological (e.g. floating kelp bodies) and human (e.g. driftwood) component. 


\section{Anthropogenic Movement as a Powerful Agent of Gene Flow}

132 Large scale human-mediated movement of marine organisms has occurred for centuries with the emergence of the first wooden ships capable of harboring communities of fouling organisms such as bryozoans, sponges, algae, barnacles, molluscs and tunicates (Carlton, 1989). After the twentieth century, the 'dry' ballast of ships was later replaced with water which allowed planktonic organisms including the larval stages of a variety of species to be pumped in and transported to sites located thousands of kilometers away from their native habitats. Surveys by Carlton (1989) and colleagues at the Oregon Institute of Marine Sciences had found over 200 species in ship ballast destined for Oregon from Japan; all of which survived the trip. Also, a report by Chu et al. (1997) found a total of 81 species distributed among five cargo containers in the Pacific destined for Hong Kong. In the last twenty years however, there has been a fourfold increase in the growth of transoceanic shipping, partly driven by technological advancements that have produced larger and faster ships and partly by the rapid pace of globalization that has opened up new international trade routes (Tournadre, 2014; Cope et al., 2015) (Figure 2A). For example, a recent survey of hull fouling by Ashton et al. (2016) estimated 680,000 arrivals per year of barnacle species at ports distributed across the Atlantic and the Pacific coasts. Considering that only 15 commercial vessels were sampled, it is likely that this number was an underestimate. The most important ecological consequence of transoceanic shipping is the increased introductions of NIS which has subsequently resulted in higher rates of invasion events (Roman \& Darling, 2007). of organisms both regionally and globally (Elton 1995; Grosholz et al. 2015). Commercial shellfish such 151 as oysters, abalone and mussels are often transported across long distances for transplantation purposes 152 (Figure 2B). These shellfish may harbor a variety of organisms which can reside within or inside crevices 153 of the shells, in mudpacks that accompany brood stocks or even within the organism itself. For example, 154 the introduction of the Pacific oyster Crassostrea gigas to Europe resulted in the arrival of more than a 155 dozen NIS, with about five or six eventually becoming established (Wolff \& Reise, 2002). In a more 
recent episode, the polychaete Diopatra biscayensis in France was able to expand its range across a phylogeographic break due to anthropogenic transport on mussel seed ropes (Woodin et al., 2014).

While marine invasions are an important consequence of anthropogenic movement of NIS, a more conspicuous phenomenon is the erosion of phylogeographic signal due to continuous and consistent movement of migrants (Wares et al., 2002; Dawson et al., 2005; David et al, 2016; Wrange et al. 2016). This phenomenon is coined as 'cryptic dispersal' since the anthropogenic effect cannot be definitively detected by genetic patterns alone (David et al., 2016). Cryptic dispersal is primarily driven by propagule pressure and also by the coastal environment, specifically the strength of phylogeographic breaks. If two distinct populations of a species are separated by a strong break, isolated introductory events that exchanges propagules from both populations will probably not significantly alter genetic structure and such introductions could be easily detected by genetic markers (Darling et al., 2008; Reitzel et al., 2008; Reusch et al., 2010). However, if these introductory events become continuous and consistent, closely mimicking metapopulation migration models (e.g. stepping stone and island models), then phylogeographic signal may become eroded, driving down Wright's fixation index $\left(\mathrm{F}_{\mathrm{ST}}\right.$ values $)$ and giving the illusion of low genetic structure and high connectivity. Furthermore, if cryptic dispersal has been occurring across longer timescales, even genetic patterns inferred from mtDNA may be obscured via reshuffling of ancient haplotypes due to past translocation events (Wrange et al. 2015; David et al., 2016; Williams et al. 2016).

Cryptic dispersal highlights an important limit to population genetics, which is that the movement of genes does not necessarily correlate with natural movement. This is an important point because it opens up the possibility of drawing grossly inaccurate interpretations of dispersal patterns from genetic data in regions where distinct barriers exist. Perhaps the most vulnerable population genetic studies are those that 'detect' a panmictic population, which is defined as naturally dispersed endemic populations that freely interbreed due to the absence of dispersal barriers. In these studies, introductory events may be suggested as an after-thought or never at all and the lack of structure is usually attributed to the species' 'strong dispersal capabilities'. For example, studies by Wrange et al. (2016) found high frequency of 

improvisus which produces planktonic larvae. This genetic pattern was primarily attributed to anthropogenic dispersal mechanisms, despite the fact that the authors were unable to definitively distinguish between oceanographic connectivity and anthropogenic dispersal. Another recent genetic study by Hudson et al. (2016) found little genetic differentiation in the tunicate Ciona intestinalis which exhibits abbreviated development. Interestingly, this study was carried out in $C$. intestinalis' native range but again, the authors were unable to determine whether the observed genetic pattern was attributed to anthropogenic or natural dispersal. An interesting phylogenetic and phylogeographic study by Ciotir \& Freeland (2016) on invasive cattails recently described the process of 'cryptic intercontinental dispersal' where the horticulture trade was responsible for the widespread dispersal of a variety of cattail species. However, like the previous two studies, much of the data on phylogeographic signal was inconclusive. The most obvious solution to the cryptic dispersal problem will be the development of a tool that can discern the relative contribution of both natural and anthropogenic dispersal types to the observed genetic patterns of a population. To accomplish this from the anthropogenic side one would need to be able to quantify the number of migrants of the study species being carried in each ship's ballast per route.

197 However, considering the sheer amount of shipping traffic that occurs along a typical coastal system combined with the millions of tons of ballast water that are pumped in and out per trip - even with environmental DNA (eDNA) as a monitoring tool for identification, such a task would be logistically impossible. An interesting study by Darling et al. (2012) attempted to investigate possible correlations between vector patterns and genetic connectivity of an invasive tunicate (Styela clava) in the northeastern Pacific. The authors compiled shipping data (specifically vessel routes) for the northeastern Pacific which was then used to create a shipping connectivity matrix of the region. Their results showed that the genetic data failed to capture the anthropogenic effects of shipping, which supports the aforementioned view that such an approach for evaluating cryptic dispersal is problematic and in many cases impractical. With respects to aquaculture, the task of tracking shellfish movement is considerably less onerous than large 207 transoceanic shipping vessels. In addition, the shellfish in a brooding stock that were transplanted can be 
208

209

210

211

212

213

214

215

216

217

218

219

220

221

222

223

224

225

226

227

228

229

230

231

232

233

examined individually and the target hitchhiker species can be quantified and processed for genetic studies. However, there are currently no known studies that have carried out experimental transplants to this extent and is therefore an area ripe for future research.

\section{Evolutionary Consequences of Cryptic Dispersal}

Populations that are separated by phylogeographic breaks are genetically differentiated units that are locally adapted to their environment (Irwin, 2012). While these distinct units may show some level of phenotypic divergence such as size or colour variation, gene-flow 'leakage' across dispersal barriers is enough to prevent speciation events. In a system where cryptic dispersal is occurring, we would expect that these dispersal barriers will be weakened. This weakening would occur as human-mediated transport (e.g. ballast water transfer) deliver a sufficient number of propagules to overcome local adaptation. If propagules are being transported in this manner, then populations can be homogenized via some form of reverse speciation which was defined as "a reversal of the processes that lead to the diversification of species pairs" (Taylor et al. 2006). This is important to consider because genetic homogenization ultimately results in a loss of genetic diversity. For example, in many population genetic studies, a source population is often the one that has the highest haplotype or nucleotide diversity. However, if cryptic dispersal is occurring then not only is phylogeographic signal being diluted but 'original' haplotypes of the source population are being distributed and re-distributed across multiple sink populations at a high enough frequency to obfuscate the detectability of a distinct source. If genetic variation supplies the raw material for evolution, then it follows that cryptic dispersal could reduce the evolutionary potential of an entire species. For example, a review of the aquaculture industry with regards to introductions highlighted the dangers of repeated translocations in fish stocks where such activities can reduce genetic diversity of commercially important species (Johnson, 2000).

Here, we would like to emphasize that the reduction in the evolutionary potential of a species due to cryptic dispersal is a phenomenon that is expected to occur largely in introduced species, where a history of vector transport has already been established. While dispersal in the native habitats could also 
234 be candidates, detection may be more difficult due to the longer evolutionary histories of these species.

235 Interestingly, if multiple introductions are the driving force behind the homogenization process, there is

236 the possibility that the expected reduction in genetic diversity could be buffered by individuals arriving

237 and carrying unique haplotypes from a completely different source. A recent study by Lejeusne et al.

238 (2014) illustrated such a scenario where high levels of gene flow were detected in a Palaemonid shrimp

239 using the COI genetic marker. The authors also found high genetic diversity which was attributed to

240 multiple introductions with international shipping being the culprit vector. Another recent study by David

241 et al. (2016) used the cytochrome b gene and a single nuclear locus to detect high genetic connectivity

242 among populations (no geographic patterning of haplotypes) of a shell-boring polychaete distributed

243 across three phylogeographic breaks in South Africa. The movement of oysters among aquaculture farms

244 distributed along the country's $\sim 2000 \mathrm{~km}$ coastline was identified as the main driver of this high

245 connectivity (David et al. 2016; Williams et al. 2016). Despite the high connectivity levels, genetic

246 diversity was low which was probably due to the homogenizing effect of cryptic dispersal along with a

247 lack of individuals arriving from genetically distinct sources.

Adaptability also plays an important role in the cryptic dispersal capacity of a species since

propagules would not only have to be consistently transported across phylogeographic breaks, but would

also have to survive and thrive in the different biogeographic regions. For example, in the case of $P$.

hoplura, experimental studies found that the species was capable of surviving in temperatures as low as

$25212^{\circ} \mathrm{C}$ and as high as $24^{\circ} \mathrm{C}$, with both temperatures characteristic of the Atlantic Ocean on the west coast

253 of the country and the Indian Ocean on the east coast respectively (David \& Simon, 2014). It is therefore

254 not surprising that the high genetic connectivity observed in this species could have been mistaken for

255 panmixia.

257 Integrating Ocean Models into Population Genetic Studies to Detect Cryptic Dispersal

The most practical method for assessing cryptic dispersal will involve focusing on natural

259 movement - a process which can be numerically modeled. Studies integrating high resolution larval 
transport models (LTM) into population genetic studies to measure dispersal have been on the rise in the past few years, partly due to advances in computing capabilities and the costs associated with accessing them (Viard et al. 2006; Galindo et al., 2006; Selkoe et al., 2008; Baums et al., 2006; White et al. 2010). Because LTMs incorporate the prevailing hydrographic conditions of the study area, they add a high degree of oceanographic realism to dispersal studies, which is especially important for understanding contemporary movement of larvae (Selkoe et al., 2008). LTMs coupled with population genetics offer a powerful means of assessing cryptic dispersal since a larval transport model can act as a control, depicting what connectivity patterns should look like in the absence of anthropogenic movement. Once connectivity patterns are determined based on the model, they can be cross validated with genetic patterns. One of the first comprehensive studies to utilize this approach was conducted by Dawson et al. (2005) who assessed the population structure of a supposedly highly dispersed cosmopolitan jellyfish, Aurelia sp. The authors, using mtDNA and a single nDNA loci, found high levels of genetic connectivity among global subpopulations. However, their larval transport model showed limited connectivity that coincided with

273 known phylogeographic breaks, indicating that multiple introductory events over a longer time scale, 274 possibly via shipping vectors, could have eroded the phylogeographic signal, giving the illusion of a 275 panmictic population (Dawson et al., 2005). In a similar but more recent study, David et al. (2016) found that the aquaculture trade in South Africa was facilitating genetic connectivity in the invasive polychaete

277 Polydora hoplura, which is notorious for burrowing and residing in oyster and abalone shells. The 278 authors found a lack of any clear geographic patterning of haplotypes and low $\mathrm{F}_{\mathrm{ST}}$ despite the fact that 279 populations were distributed across multiple phylogeographic breaks. However, a high-resolution 280 transport model found limited connectivity that coincided with these breaks. It was known at the time that 281 oyster farmers frequently transported their stock among farms that are widely distributed along the 282 country's coast and in a non-directional manner (Simon et al., 2006; Haupt et al., 2010). This movement 283 resulted in the polychaete being moved with the oysters, across the breaks, consequentially resulting in a 284 reduction in signal and an elimination of any geographic clustering of haplotypes (Williams et al. 2016) 285 (Figure 3). 
correlated with the model's estimate of extensive dispersal along the coast and assumed that the pattern

was a direct result of the larva's dispersal capabilities. However, this study explicitly assumed that there was no anthropogenic transport occurring and it was conducted using a 2D model on a regional scale.

High resolution LTMs are based on Lagrangian mechanics, which presents a 3D numerical representation of velocities at different depths (Siegel et al., 2003). Larvae are represented by virtual floats, which are deployed at specific localities in the model. Dispersal simulations are then carried out and repeated for a number of years using the available ocean circulation data for each year (Figure 4). Valuable data concerning connectivity patterns include dispersal trajectory and density maps along with particle capture data which can be analyzed both qualitatively and quantitatively. The complexity of the model can be increased by incorporating specific biological characteristics into the floats, such as duration in the plankton (which determines how far the floats will be carried by surface currents), mortality rates (which will determine the number of floats that would be 'captured' at a pre-determined site) and fecundity (which determines the number of floats per simulation run). The most recent generation of transport models that are often used in conjunction with population genetics is the Regional 2008). While model predictions can offer valuable insights into the 'pure' movement of larvae, it is

307 important to note that ocean models, like all computer models, do possess limitations. For example,

308 LTMs are limited by the knowledge of important ecological processes involved in dispersal. In other 309 words, how well do we know our study species? Many species, especially fishes can produce larvae that 310 do not act as passive floaters and are capable of counteracting the advective effects of currents by actively 311 adjusting their orientation in the water column or exhibiting diel vertical migrations (Levin, 2006). In 
312 such cases, incorporating appropriate life history parameters into the virtual floats along with adding

313 drag-drift effects into the simulations is essential for accurately modeling dispersal in such a species.

314 Perhaps the biggest limitation is that for models to be as accurate as possible, they need to be able to fully 315 capture coastal processes, especially nearshore circulation patterns which are responsible for determining 316 particle trajectory and supply/recruitment results.

The strength of using seascape genetics to detect cryptic dispersal lies in the power of crossvalidation. If populations show limited dispersal based on LTM estimates but show high connectivity based on the genetic data (e.g. low non-significant $\mathrm{F}_{\mathrm{ST}}$, non-significant isolation by distance and mixed haplotypes), it is likely that cryptic dispersal is occurring. However, this approach is only useful if connectivity patterns are discordant. In scenarios where high connectivity is estimated by both population genetic studies and LTMs, it would be virtually impossible to discern the contributions of anthropogenic transport to the observed genetic pattern. One possible solution would be to integrate both physical oceanography and population genetic data into a time-step model that includes an estimate of the number of propagules being transported in a vessel at any given time. As computing power continues to increase, we expect the development of these types of complex predictive models to emerge within the field of marine invasion biology, which would greatly aid in providing informative data that can be used to mitigate the loss of diversity caused by cryptic dispersal.

\section{Conclusions}

Over the last few decades, genetics has provided crucial data on the dispersal potential and connectivity patterns of a great number of species. This has given us novel insights into important marine ecological process and has challenged us to re-evaluate conservation methodologies such as the way marine reserves are designed. However, as humans continue to affect every aspect of the marine environment, especially through biological invasions, the need for cross-disciplinary collaboration is crucial in order to respond to these new challenges. Here we highlighted the phenomenon of cryptic 
eroding phylogeographic signal which gives the illusion of a naturally dispersing species. Such a phenomenon is problematic since the erosion of dispersal barriers can allow contact between spatially separated populations, thereby initiating the homogenization process. In order to solve this problem, we outlined the importance of utilizing both population genetics and larval transport models (LTMs). These

342 LTMS will not only be able to act as a control to detect cryptic dispersal but has also been shown to

343 elucidate fine scale ocean processes that can be related back to genetic patterns (Gilg \& Hilbish, 2003).

344 While previous studies have focused on the novelty of using this integrated approach (White et al., 2010), 345 here we call for such an approach to be regarded as the gold standard for evaluating connectivity patterns 346 on large and complex coastal systems.

\section{Acknowledgements}

350 We would like to thanks Dr. Jon Wares and another anonymous reviewer for greatly improving the final version of this manuscript. We would also like to thank MarineTraffic for their assistance in developing the shipping density map and Dr. Tamara Robinson for valuable input.

References

Buston P.M., D’Aloia C.C. (2013) Marine ecology: reaping the benefits of local dispersal. Current Biology 23: R351-R353.

Chu K.H, Tam P.F, Fung C.H and Chen Q.C. (1997) A biological survey of ballast water in container ships entering Hong Kong. Hydrobiologia 352: 201-206.

Ciotir C. and Freeland J. (2016) Cryptic intercontinental dispersal, commercial retailers, and the genetic diversity of native and non-native cattails (Typha spp.) in North America. Hydrobiologia 768: $137-150$. 
362

Cope R.C., Prowse T.A.A., Ross J.V, Wittmann T.A. and Cassey P. (2015) Temporal modelling of ballast water discharge and ship-mediated invasion risk to Australia. Royal Society Open Science 2: 150039.

Cowen R.K and Sponaugle S. (2009) Larval dispersal and marine population connectivity. Annual Review of Marine Science 1: 443-466.

Crook D.A., Lowe W.H., Allendorf F.W., Eros T., Finn D.S., Gillanders B.M., Hadwen W.L., Harrod C., Hermoso V., Jennings S., Kilada R.W., Nagelkerken I., Hansen M.M., Page T.J., Riginos C., Fry B., Hughes J.M. (2015) Human effects on ecological connectivity in aquatic ecosystems: integrating scientific approaches to support management and mitigation. Science of the Total Environment 534: $52-64$.

Cumming R.A., Nikula R., Spencer H.G., Waters J.M. (2014) Transoceanic genetic similarities of kelpassociated sea slug populations: long-distance dispersal via rafting? Journal of Biogeography 41: $2357-2370$.

dos Santos A., Santos M.P., Conway D.V.P., Bartilotti C., Lourenco P. and Queiroga H. (2008) Diel vertical migration of decapod larvae in the Portuguese coastal upwelling ecosystem: implications for offshore transport. Marine Ecology Progress Series 359: 171-183

Darling J.A., Bagley M.J., Roman J., Tepolt C.K. and Geller G.B. (2008). Genetic patterns across multiple introductions of the globally invasive crab genus Carcinus. Molecular Ecology 17: 4992-5007.

Darling J.A., Herborg L.M. and Davidson I.C. (2012) Intracoastal shipping drives patterns of regional population expansion by and invasive marine invertebrate. Ecology and Evolution 2: 2557-2566.

David A.A., Matthee C.A., Loveday B.R. and Simon C.A. (2016) Predicting the dispersal potential of an invasive polychaete pest along a complex coastal biome. Integrative and Comparative Biology 56: $600-610$.

David A.A. and Simon C.A. (2014) The effect of temperature on larval development of two nonindigenous poecilogonous polychaetes (Annelida: Spionidae) with implications for life-history 
theory, establishment and range expansion. Journal of Experimental Marine Biology and Ecology 461: $20-30$.

Dawson M.N., Gupta A.S. and England M.H. (2005) Coupled biophysical global ocean model and molecular genetic analyses identify multiple introductions of cryptogenic species. Proceedings of the National Academy of Sciences of the United States of America 102: 11968-11973.

Elton C.S. (1958) The ecology of invasions by animals and plants. Methuen, London, England. 181 pp.

Galindo H.M., Olson D.B. and Palumbi S.R. (2006) Seascape genetics: a coupled oceanographic-genetic model predicts population structure of Caribbean corals. Current Biology 1622-1626.

Gilg M.R. and Hilbish T.J. (2003) The geography of marine larval dispersal: coupling genetics with finescale physical oceanography. Ecology 84: 2989-2998.

Grosholz E.D., Crafton R.E., Fontana R.E., Pasari J.R.,Williams S.L.and Zabin CJ (2015) Aquaculture as a vector for marine invasions in California. Biological Invasions 17: 1471-1484.

Haupt T.M., Griffiths C.L., Robinson T.B. and Tonin A.F.G. (2010) Oysters as vectors of marine alines, with notes on four introduced species associated with oyster farming in South Africa. African Zoology 45: 52-62.

Hellberg M.E. (2009) Gene flow and isolation among populations of marine animals. Annual Review of Ecology, Evolution and Systematics 40: 291-310.

Hellberg M.E., Burton R.S., Neigel J.E. and Palumbi S.R. (2002) Genetic assessment of connectivity among marine populations. Bulletin of Marine Science 70: 273 - 290.

Hudson J., Viard F., Roby C. and Rius M. (2016) Anthropogenic transport of species across native ranges: unpredictable genetic and evolutionary consequences. Biology Letters 12: 20160620.

Karl S.A., Toonen R.J., Grant W.S. and Bowen B.W. (2012) Common misconceptions in molecular ecology: echoes of the modern synthesis. Molecular Ecology 21: $4171-4189$.

Kesaniemi J.E., Hansen B.W., Banta G.T. and Knott K.E. (2014) Chaotic genetic patchiness and high relatedness of a poecilogonous polychaete in a heterogenous estuarine landscape. Marine Biology 161: $2631-2644$. 
414 Levin LA. (2006) Recent progress in understanding larval dispersal: new directions and digressions. Integrative and Comparative Biology 46: 282-297.

McDonald K.M., Winter D.J., Ashcroft A.L. and Spencer H.G. (2015) Phylogeography of the whelk genus Cominella (Gastropoda: Buccinidae) suggests long-distance counter-current dispersal of a direct developer. Biological Journal of the Linnaean Society 115: 315-332.

Metaxas A. and Saunders M. (2009) Quantifying the "Bio-" components in biophysical models of larval transport in marine benthic invertebrates: advances and pitfalls. Biological Bulletin 216: 257-272.

Nikula R., Spencer H.G. and Waters J.M. (2013) Passive rafting is a powerful driver of transoceanic gene-flow. Biology Letters 9: 20120821.

Palumbi S.R. (2003) Population genetics, demographic connectivity, and the design of marine reserves. Ecological Applications 13: 146-158.

Pfeiffer-Herbert A.S., McManus M.A., Raimondi P.T., Chao Y. and Chai F. (2007) Dispersal of barnacle larvae along the central California coast: a modeling study. Limnology and Oceanography 52: $1559-1569$.

Pringle J.M. and Wares J.P. (2007) Going against the flow: maintenance of alongshore variation in allele frequency in a coastal ocean. Marine Ecology Progress Series 335: 69 - 84.

Reitzel A.M., Darling J.A., Sullivan J.C. and Finnerty J.R. (2008) Global population genetic structure of the starlet anemone Nematostella vectensis: multiple introductions and implications for conservation policy. Biological Invasions 10: 1197-1213.

Reusch T.B.H., Bolte S., Sparwel M., Moss A.G.and Javidpour J. (2010) Microsatellites reveal origin and genetic diversity of Eurasian invasions by one of the world's most notorious marine invader, Mnemiopsis leidyi (Ctenophora). Molecular Ecology 19: 2690-2699.

Shchepetkin A. and McWilliams J. (2005) The Regional Oceanic Modeling System (ROMS): a splitexplicit, free-surface, topography-following-coordinate ocean model. Ocean Model 9: 347-404.

Selkoe K.A., Henzler C.M. and Gaines S.D. (2008) Seascape genetics and the spatial ecology of marine populations. Fish and Fisheries 9: 363-377. 
440

441

442

443

444

445

446

447

448

449

450

451

452

453

454

455

456

457

458

459

460

461

462

463

464

465

Selkoe K.A. and Toonen R.J. (2011) Marine connectivity: a new look at pelagic larval duration and genetic metrics of dispersal. Marine Ecology Progress Series 436: 291 - 305 .

Siegel D.A., Kinland B.P., Gaylord B. and Gaines S.D. (2003) Lagrangian descriptions of marine larval dispersion. Marine Ecology Progress Series 260: 83-96.

Simon C.A., Ludford A. and Wynne S. (2006) Spionid polychaetes infesting cultured abalone, Haliotis midae, in South Africa. African Journal of Marine Science 28: 167-171.

Teske P.R., Von der Heyden S., McQuaid C.D. and Barker N.P. (2011) A review of marine phylogeography in southern Africa. South African Journal of Science 107: 43-53.

Viard F., Ellien C. and Dupont L. (2006) Dispersal ability and invasion success of Crepidula fornicata in a single gulf: insights from genetic markers and larval-dispersal model. Helgoland Marine Research 60: 144-152.

Von der Heyden S. (2009) Why do we need to integrate population genetics into South African marine protected area planning? African Journal of Marine Science 31: 263-269.

Wares J.P. and Pringle J.M. (2008) Drift by drift: effective population size is limited by advection. BMC Evolutionary Biology 8: 235

White C., Selkoe K.A., Watson J., Siegel D.A., Zacherl D.C. and Toonen R.J. (2010) Ocean currents help explain population genetic structure. Proceedings of the Royal Society of London B DOI: 10.1098/rspb.2009.2214.

Wrange A.L., Charrier G., Thonig A., Alm Rosenblad M., Blomberg A., Havenhand J.N., Jonsson P.R. and Andre C. (2016) The story of a hitchhiker: population genetic patterns in the invasive barnacle Balanus (Amphibalanus) improvisus Darwin 1854. PLoS One 11: e0147082.

Wysor B., Kooistra H.C.F Wiebe, Fredericq S. (2002) Comparative phylogeography of reticulate cladophoralean algae. Journal of Phycology 38: 38 - 39 . 
466 Figure Legends

467 Fig 1. Examples of phylogeographic breaks on the southern African coast. Breaks coincide with major the 468 biogeographic boundaries that separate cool-temperate waters of the Atlantic coast from the warm469 temperate south coast and the warm-temperate south coast from the sub-tropical and tropical coasts of the 470 Indian Ocean. Map modified from Teske et al. (2011)

472 Fig. 2. A) Overall Density Map showing global vessel traffic for the year 2015 based on AIS satellite data 473 and B) Batch of farmed oysters from offshore cultivation beds in Saldanha Bay, South Africa.

475 Fig 3. Cryptic dispersal of the shell-boring polychaete Polydora hoplura in South Africa via the 476 aquaculture trade. South Africa. Step 1: planktotrophic larvae enters shellfish farm through the inflow, 477 step 2: larvae settles, undergo metamorphosis and burrows into farmed oysters, step 3: infested oysters are 478 transported to geographically distant farm, step 4: brooding females release larvae into the water column, 479 step 5: fraction of larvae escapes into the wild via the outflow. Dashed arrows refer to spat or adult 480 oysters imported into the farm (locally and internationally) and exported to other farms in the region.

482 Fig. 4. Ocean circulation model built using the Regional Oceanic Modeling System (ROMS). Model 483 shows 289,788 possible trajectories of virtual floats that were recovered after being deployed at three sites 484 along the southern African coast (Jacobsbaai, Hermanus and Haga Haga) with the Cape Point 485 phylogeographic break highlighted. Total of 1271 floats were deployed each month from 1991-2010. 


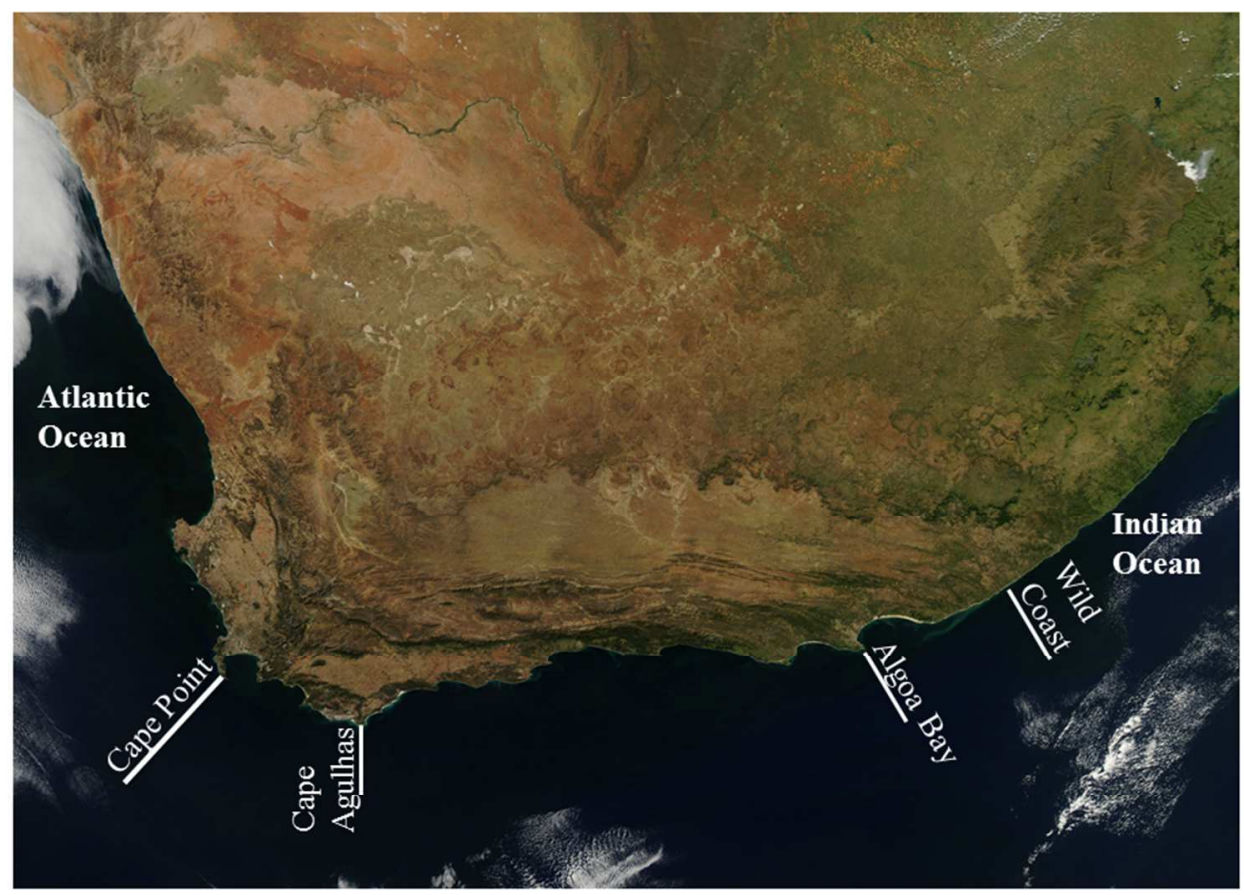

Fig 1. Examples of phylogeographic breaks on the southern African coast. Breaks coincide with major the biogeographic boundaries that separate cool-temperate waters of the Atlantic coast from the warmtemperate south coast and the warm-temperate south coast from the sub-tropical and tropical coasts of the Indian Ocean. Map modified from Teske et al. (2011)

$254 \times 190 \mathrm{~mm}(96 \times 96$ DPI $)$ 

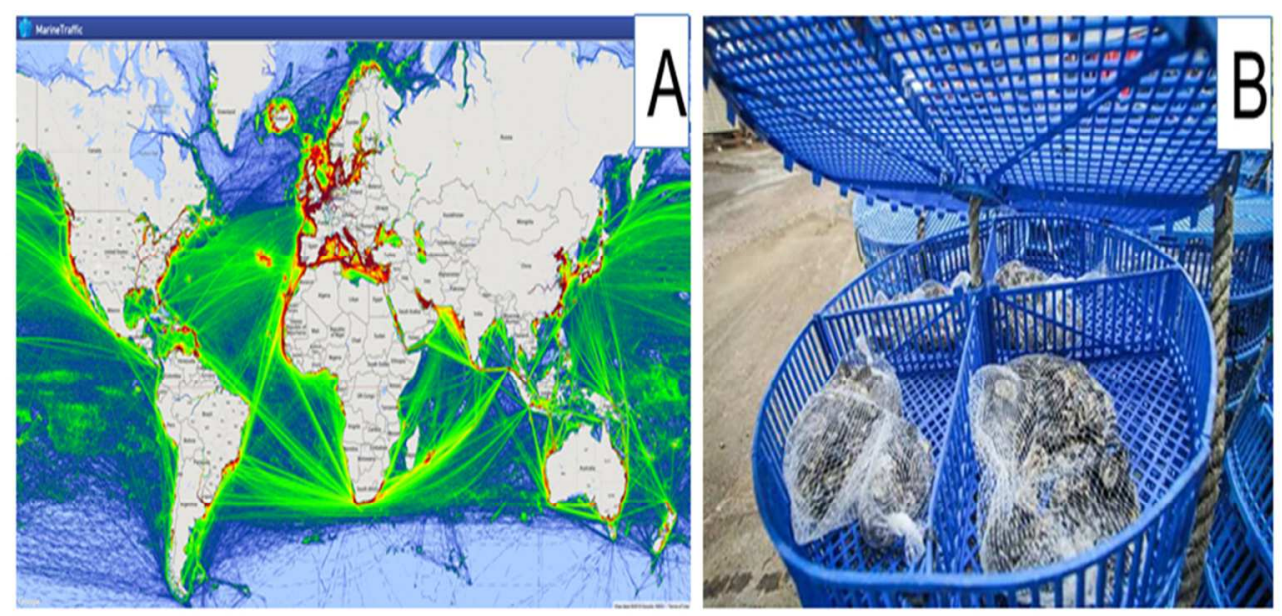

Fig. 2. A) Overall Density Map showing global vessel traffic for the year 2015 based on AIS satellite data and B) Batch of farmed oysters from offshore cultivation beds in Saldanha Bay, South Africa.

$254 \times 77 m m(96 \times 150$ DPI $)$ 


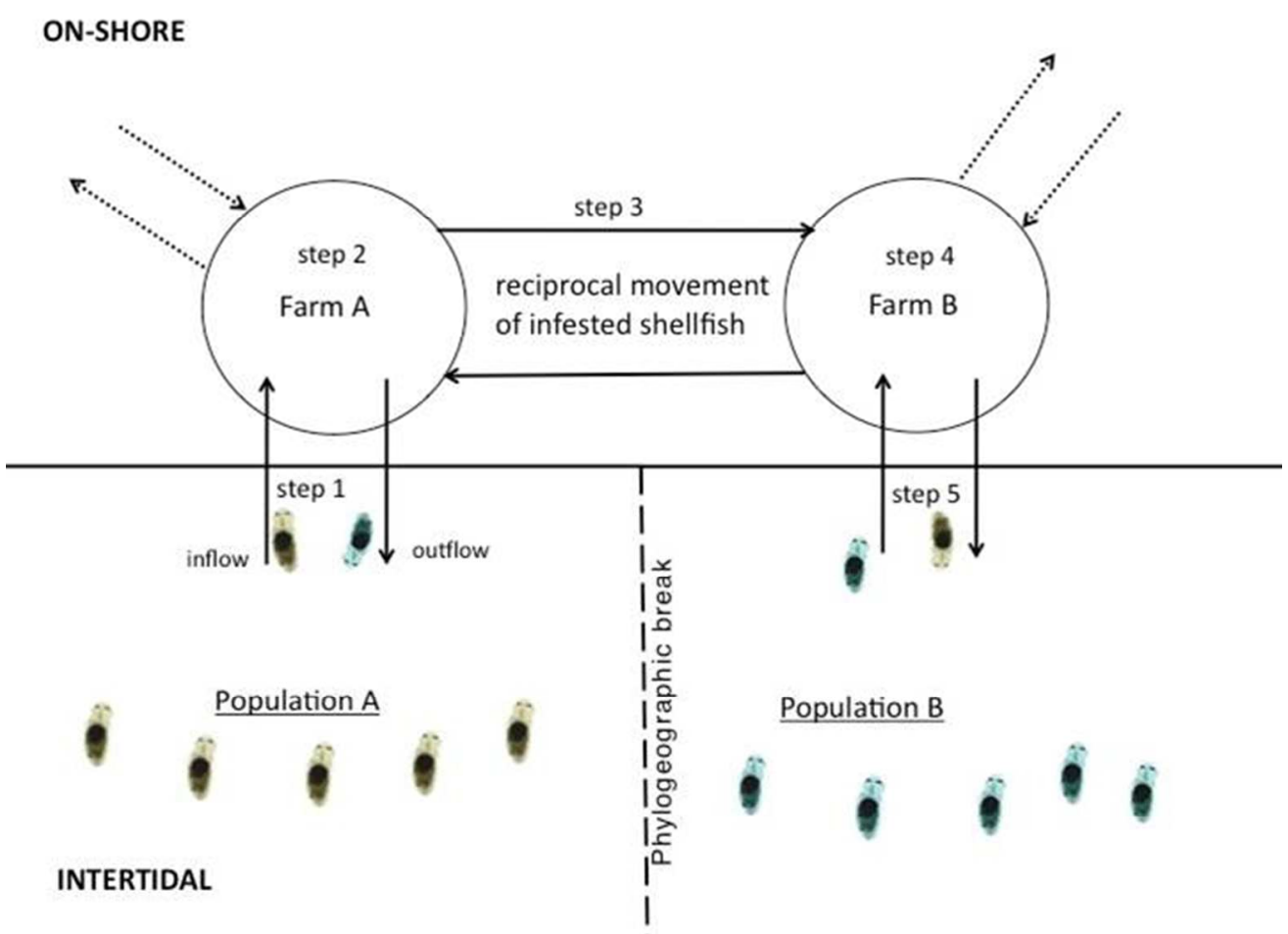

Fig 3. Cryptic dispersal of the shell-boring polychaete Polydora hoplura in South Africa via the aquaculture trade. South Africa. Step 1: planktotrophic larvae enters shellfish farm through the inflow, step 2: larvae settles, undergo metamorphosis and burrows into farmed oysters, step 3: infested oysters are transported to geographically distant farm, step 4: brooding females release larvae into the water column, step 5: fraction of larvae escapes into the wild via the outflow. Dashed arrows refer to spat or adult oysters imported into the farm (locally and internationally) and exported to other farms in the region.

$143 \times 108 \mathrm{~mm}(127 \times 127 \mathrm{DPI})$ 

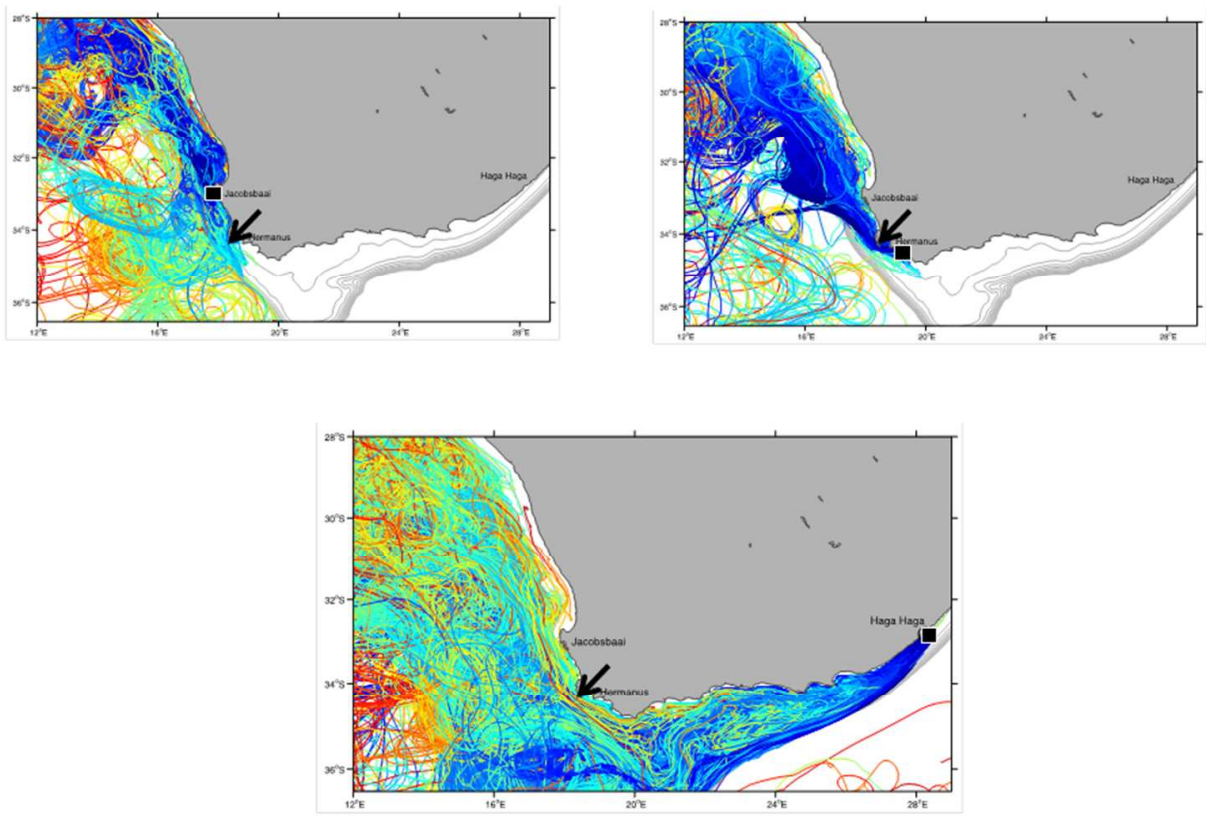

Fig. 4. Ocean circulation model built using the Regional Oceanic Modeling System (ROMS). Model shows 289,788 possible trajectories of virtual floats that were recovered after being deployed at three sites along the southern African coast (Jacobsbaai, Hermanus and Haga Haga) with the Cape Point phylogeographic break highlighted. Total of 1271 floats were deployed each month from 1991-2010.

$254 \times 190 \mathrm{~mm}(96 \times 96 \mathrm{DPI})$ 